\title{
MONOTONIC BEHAVIOUR OF TYPICAL AL-CU-MG ALLOY PRE-STRAINED AT ELEVATED TEMPERATURE
}

\author{
Adam Tomczyk, Andrzej Seweryn, Michą Doroszko \\ Bialystok University of Technology, Faculty of Mechanical Engineering, Bialystok, Poland \\ e-mail: a.tomczyk@pb.edu.pl; a.seweryn@pb.edu.pl; m.doroszko@pb.edu.pl
}

\begin{abstract}
This paper presents results of monotonic tensile and creep tests conducted on typical $\mathrm{Al}-\mathrm{Cu}-\mathrm{Mg}$ alloy (commercial 2024) specimens. Tensile tests carried out at room $\left(20^{\circ} \mathrm{C}\right)$ and elevated $\left(100^{\circ} \mathrm{C}, 200^{\circ} \mathrm{C}, 300^{\circ} \mathrm{C}\right)$ temperatures made it possible to determine strength properties of the material (Young's modulus, yield stress, ultimate tensile strength). Creep tests were performed at elevated temperature $\left(100^{\circ} \mathrm{C}, 200^{\circ} \mathrm{C}\right.$ and $\left.300^{\circ} \mathrm{C}\right)$ with a constant force. In order to obtain material creep characteristics, creep-rupture tests were carried out. Then creep tests were conducted with two different strain values: one corresponding to the beginning of the secondary creep and the other corresponding to a certain value of the tertiary creep. After preliminary creep deformation at two various strain levels, specimens were cooled at ambient temperature and then subjected to monotonic tensile tests. The characteristics of the material were obtained for pre-strained specimens at different temperatures. Specimens fracture surfaces obtained as a result of tensile (at elevated and room temperature), creep and combined tests were analyzed.
\end{abstract}

Keywords: creep and tensile tests, metals and alloys, scanning electron microscopy, numerical calculations, mechanical properties

\section{Introduction}

EN-AW 2024 aluminum alloy finds widespread applications in mechanical engineering and, particularly, in aviation. It is commonly used in the aerospace industry, e.g. as a structural element of a wing or fuselage. At high cruising speeds, temperature of these components can rise to $120^{\circ} \mathrm{C}$ (Chakherlou et al., 2010). For riveted joints and earlier cold expansion, elevated temperatures may cause creep and stress relaxation. Aluminum alloys are widely used as housings for coreless low-speed wind turbine generators. The operating temperature of generators, when the maximum power is reached, may exceed $250^{\circ} \mathrm{C}$ (Karakas and Szusta, 2016). As a result of speed of rotation, centrifugal forces may cause creep. After cooling to ambient temperature, the material is already different from the original.

Numerous studies concerning mechanical properties of 2024 aluminum alloy, particularly strength and durability, are conducted. Considering the criterion of the type of load acting on structural elements, studies can be divided into several groups related to loadings: monotonic, including elements with notches (e.g. Derpenski and Seweryn, 2011; Haigen et al. 2017), fatigue (e.g. Kowalewski et al., 2014; Szusta and Seweryn, 2017), dynamic (e.g. Kumar et al., 2011; Wang et al., 2013), creep (and relaxation) (e.g. Lumley et al., 2002; Lin et al. 2013a).

Studies of Zhao et al. (2013) and Naimi et al. (2013) presented results of investigations of the effect of high, cold plastic deformation succeeded by aging at elevated temperature on the strength parameters of alloy 2024. The effect of creep time, temperature and preliminary loadings on hardness and yield point was the subject of many other studies (Ro et al., 2006; Li et al., 2010; Guo et al., 2013). Results of such tests, conducted on alloy 7B04-T7451, were presented by Li et al. (2010). There, a significant change of the yield point was obtained, depending 
on aging conditions. Increasing preliminary load and aging time (with constant temperature $150^{\circ} \mathrm{C}$ ) caused the yield point $\left(\sigma_{y}\right)$ to increase at an aging time up to 5 hours. After that time was exceeded, the value of $\sigma_{y}$ was reduced, and that reduction was higher when higher loadings were applied during aging. Guo et al. (2013) compared hardness of alloy 7075 subjected to prior purely thermal loadings with the hardness of alloy subjected to thermo-mechanical loadings. Lower hardnesses were obtained for thermal aging at temperatures lower than $140^{\circ} \mathrm{C}$. Above that temperature, specimens previously subjected to thermo-mechanical loadings exhibited greater hardness. The paper by Ro et al. (2006) presented test results relating to the effect of aging at the same temperature but for different times on the plastic properties and hardness of alloy 2024 . They showed a decrease of the yield point for short aging times, an increase for medium times, and a decrease once again for long times. The effect of pre-deformation at various temperatures on the value of the yield point, ultimate tensile strength and elongation of the same alloy was presented by Lin et al. (2014). A decrease of the yield point and ultimate tensile strength was observed for pre-deformation of $185-225 \mathrm{MPa}$ at a temperature of $200^{\circ} \mathrm{C}$ while for lower stress values, that difference was greater. In turn, preliminary loading at $150^{\circ} \mathrm{C}$ and $170^{\circ} \mathrm{C}$ improved the value of both the yield point and ultimate tensile strength. The effect was reversed for elongation: pre-deformation at $200^{\circ} \mathrm{C}$ increased elongation, and at lower temperatures - reduced elongation. Wang et al. (2016) described results of investigations on the effect of preliminary compressive strains (3\% and 5\%) during aging of alloy 2219 at a temperature of $175^{\circ} \mathrm{C}$ on its mechanical properties. A significant increase of both the yield point and tensile strength was obtained relative to the material subjected only to thermal aging. Chen et al. (2012) presented test results for alloy 7050 concerning thermal $\left(160^{\circ} \mathrm{C}\right)$ and thermo-mechanical loadings for different aging times. Different values of strength parameters were obtained depending on the share of mechanical loads (age-formed) or lack thereof (stress-free aging) in the preliminary ageing process. The yield point decreased as a result of the action of external loadings during the ageing process, while tensile strength generally increased. The longest aging time $(24 \mathrm{~h})$ was the exception, leading to a reduction of tensile strength. The material elongation decreased significantly when preliminary loadings occurred. Papers by Yang et al. $(2016,2017)$ concerned tests of alloy 2219. The influence of creep pre-deformation at a constant temperature $\left(165^{\circ} \mathrm{C}\right)$ at different load levels and for different aging times on the material yield point value was analyzed in those papers. Compared to the material without pre-deformation, i.e. subjected only to the action of temperature, the yield point of the material with pre-deformation increased nearly two-fold for short aging times. That difference decreased as aging time increased. The highest differences were obtained for the lowest preliminary tensile loads, i.e. $120 \mathrm{MPa}$. A model was also proposed allowing for determination of the yield point of the material previously subjected to thermo-mechanical loadings, among other things. A proposal of a model accounting for the effects of pre-deformation at elevated temperatures was also presented by Zhang et al. (2013). It was verified successfully on alloy 2124. Similar models have been verified experimentally for several 7XXX series alloys (Ho et al., 2004; Zhan et al., 2011; Singh et al., 2016).

The fundamental goal of the tests presented in this paper is to investigate the effect of creep pre-deformation of specimens made of EN AW-2024 (T3511) aluminum alloy on strength properties at room temperature. The results of monotonic tensile tests conducted on specimens at room temperature and at elevated temperature $\left(100^{\circ} \mathrm{C}, 200^{\circ} \mathrm{C}, 300^{\circ} \mathrm{C}\right)$ are presented here. These results made it possible to determine basic material characteristics of the studied alloy. The next part concerns tests of preliminary material creep at elevated temperature $\left(100^{\circ} \mathrm{C}, 200^{\circ} \mathrm{C}, 300^{\circ} \mathrm{C}\right)$ and at various strain levels. The stage after that consists of monotonic tensile tests conducted on specimens subjected to preliminary creep at room temperature, enabling determination of strength parameters of the material with pre-deformation. Most of papers in this field focus on the effect of initial creep carried out at temperatures of $150-200^{\circ} \mathrm{C}$ on properties of the analyzed alloy (Ro et al., 2006; Lin et al., 2013b, 2014). The research presented in this paper 
concerns pre-deformation realized at both $200^{\circ} \mathrm{C}$ temperature and $100^{\circ} \mathrm{C}$ and above all - at $300^{\circ} \mathrm{C}$ temperature. It should also be noted that in the case of low creep temperature $\left(100^{\circ} \mathrm{C}\right)$, high load values are used. Thus, here the dominant effect deciding on the later properties of the material is not the temperature effect but the mechanical one. The most important results concern predeformation at $300^{\circ} \mathrm{C}$. Initial creep carried out at this level and its effect on monotonic properties of alloy 2024 still remains not fully investigated.

\section{Test stand and specimens}

EN AW-2024 aluminum alloy in form T3511 was used in the tests. Bars with length of $3 \mathrm{~m}$ and diameter of $16 \mathrm{~mm}$ were prefabricated for making axisymmetric specimens. According to attestation, the material was hardened $\mathrm{AlCu}_{4} \mathrm{Mg}$, and the rod was manufactured by extrusion. The material chemical composition was: $\mathrm{Si}(0.13 \%), \mathrm{Fe}(0.25 \%), \mathrm{Cu}(4.4 \%), \mathrm{Mn}(0.62 \%), \mathrm{Mg}(1.7 \%)$, Cr (0.01\%), Zn (0.08\%), Ti (0.05\%).

Specimens applied in monotonic tensile and creep tests were characterized by identical shape and dimensions. Gauge length and diameter dimensions were $13 \mathrm{~mm}$ and $6.5 \mathrm{~mm}$, respectively. The gripped part of specimens was threaded, as dictated by the design of the creep testing machine (threaded pull rods).

Monotonic tensile tests and creep tests were conducted on a 4-column Kappa 100 SS creep testing machine from the Zwick/Roell with an electro-mechanical drive. An electric Maytec furnace with three heating zones, with a temperature range up to $900^{\circ} \mathrm{C}$, controlled by universal Zwick/Roell controller was used for tests at elevated temperature. A device specially designed and made for measuring deformations was used (Tomczyk and Koniuszewski, 2017). This device allowed for measurement of specimen deformations at elevated temperature by means of any gauge (e.g. extensometer) serving for measurement of strains at room temperature. Axial extensometer (Epsilon 3542050M-50-ST) with a variable measuring base of 25/50 mm and a range of $+25 \mathrm{~mm}$ and $-5 \mathrm{~mm}$ was used in cooperation with the grip described above.

\section{Results of tests}

\subsection{Monotonic tensile and creep-rupture tests for the material with no pre-deformation}

In order to determine basic strength parameters of the material at elevated temperature $\left(100^{\circ} \mathrm{C}, 200^{\circ} \mathrm{C}, 300^{\circ} \mathrm{C}\right)$ and room temperature $\left(20^{\circ} \mathrm{C}\right)$, monotonic tensile tests were conducted on a series of three specimens at each temperature according to EN ISO 6892-1 (2016) and EN ISO 6892-2 (2011). Results in the form of averaged nominal (engineering) tensile curves and true curves $\sigma_{1}=\sigma_{1}\left(\varepsilon_{1}\right)$ and $\sigma_{e q}=\sigma_{e q}\left(\varepsilon_{e q}\right)$ are given in Fig. 1 .

It should be added that true stress-strain curves were obtained on the basis of numerical calculations using the finite element method, since the average experimental relation between load and displacement of the gauge length was known. The MSC.Marc software package was used for simulations, while the procedure of curve determination was similar to the procedure described by Derpenski and Seweryn (2011). The elastic-plastic material model with isotropic hardening and the Huber-von Mises yield criterion was applied in that procedure. This made it possible to obtain principal stress and strain $\left(\sigma_{1}, \varepsilon_{1}\right)$ as well as equivalent stress and strain $\left(\sigma_{e q}, \varepsilon_{e q}\right)$ according to the Huber-von Mises hypothesis.

Average values of basic parameters, such as Young's modulus $E$, yield point $\sigma_{y}$, ultimate tensile strength $\sigma_{u}$, strain $\varepsilon_{u}$ (corresponding to $\sigma_{u}$ ), strain at break $\varepsilon_{B}$ are presented in Table 1 . It should be noted that values $\sigma_{c}$ and $\varepsilon_{c}$ correspond to the maximum values of principal true stress $\sigma_{1}$ and strain $\varepsilon_{1}$ were obtained based on the true stress-strain curves. 


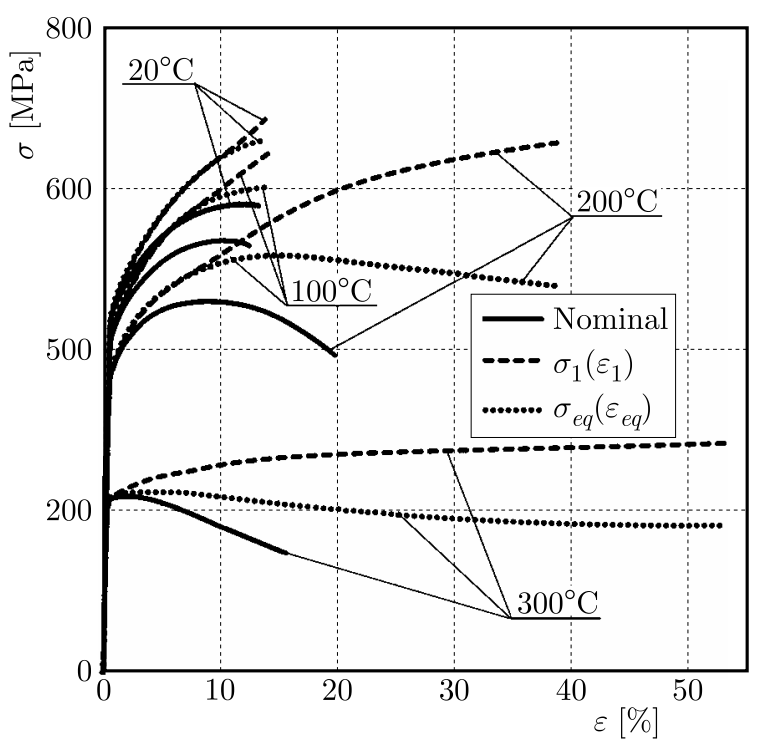

Fig. 1. Nominal (continuous line), actual $\sigma_{1}=\sigma_{1}\left(\varepsilon_{1}\right)$ (dashed line) and $\sigma_{e q}=\sigma_{e q}\left(\varepsilon_{e q}\right)$ (dotted line) monotonic tensile curves obtained at different temperatures for specimens without creep pre-deformation

Table 1. Values of strength parameters at various temperatures (based on nominal tensile curves) as well as the critical stress and strain value $\sigma_{c}, \varepsilon_{c}$ (based on the true curve $\sigma_{1}=\sigma_{1}\left(\varepsilon_{1}\right)$ )

\begin{tabular}{|c|c|c|c|c|c|c|c|}
\hline$T\left[{ }^{\circ} \mathrm{C}\right]$ & $E[\mathrm{GPa}]$ & $\sigma_{y}[\mathrm{MPa}]$ & $\sigma_{u}[\mathrm{MPa}]$ & $\sigma_{c}[\mathrm{MPa}]$ & $\varepsilon_{u}[\%]$ & $\varepsilon_{B}[\%]$ & $\varepsilon_{c}[\%]$ \\
\hline \hline 20 & 74 & 447 & 580 & 686 & 12.1 & 13.3 & 13.8 \\
\hline 100 & 71 & 418 & 536 & 647 & 10.3 & 12.7 & 14.5 \\
\hline 200 & 70 & 372 & 460 & 657 & 9.1 & 19.8 & 38.7 \\
\hline 300 & 56 & 214 & 219 & 283 & 2.1 & 17.0 & 52.9 \\
\hline
\end{tabular}

Fracture surfaces of specimens subjected to tension at temperatures of $20^{\circ} \mathrm{C}$ and $100^{\circ} \mathrm{C}$ are essentially similar in nature (Fig. 2). Nevertheless, it is clearly visible that the fracture plane angle of orientation relative to the specimen axis is close to $45^{\circ}$, which suggests that shear stress has the main influence on the failure process. The fracture surface is smooth (with low roughness), however, at the highest magnification, remnants left behind by growing micro-voids and sheared bridges between them are visible. Damage initiation took place as a result of the maximum principal stress $\sigma_{1}$ occurrence exactly on the specimen axis.

Further, sudden development of damage based on final shearing of the bridges between voids was dictated by the action of the maximum shear stress. Numerous, unevenly distributed precipitates can be observed in dimples, and they are significantly responsible for the material hardening. The damage initiation process usually begins at the boundary between the matrix and the coarse precipitate (e.g. Li et al., 2013).

Specimen fractures obtained in monotonic tensile tests at temperatures of $200^{\circ} \mathrm{C}$ and $300^{\circ} \mathrm{C}$ are completely different in nature (Fig. 3a). Here, two fracture planes are clearly visible. In the central part, the plane is perpendicular to the specimen axis and has a fibrous character with clearly visible dimples, which are remnants after voids that grew in the loading direction and were ruptured. This fracture plane is distinguished by high roughness. In the case of the fracture surface obtained at $200^{\circ} \mathrm{C}$, this roughness is clearly lower than on the surface of the fracture obtained at $300^{\circ} \mathrm{C}$. The second plane of failure is oriented at an angle of $45^{\circ}-50^{\circ}$ relative to the specimen axis, and its surface is visibly smoother than the previous surface. It links the central plane, corresponding to ductile fracture, with the free exterior surface of the specimen. 

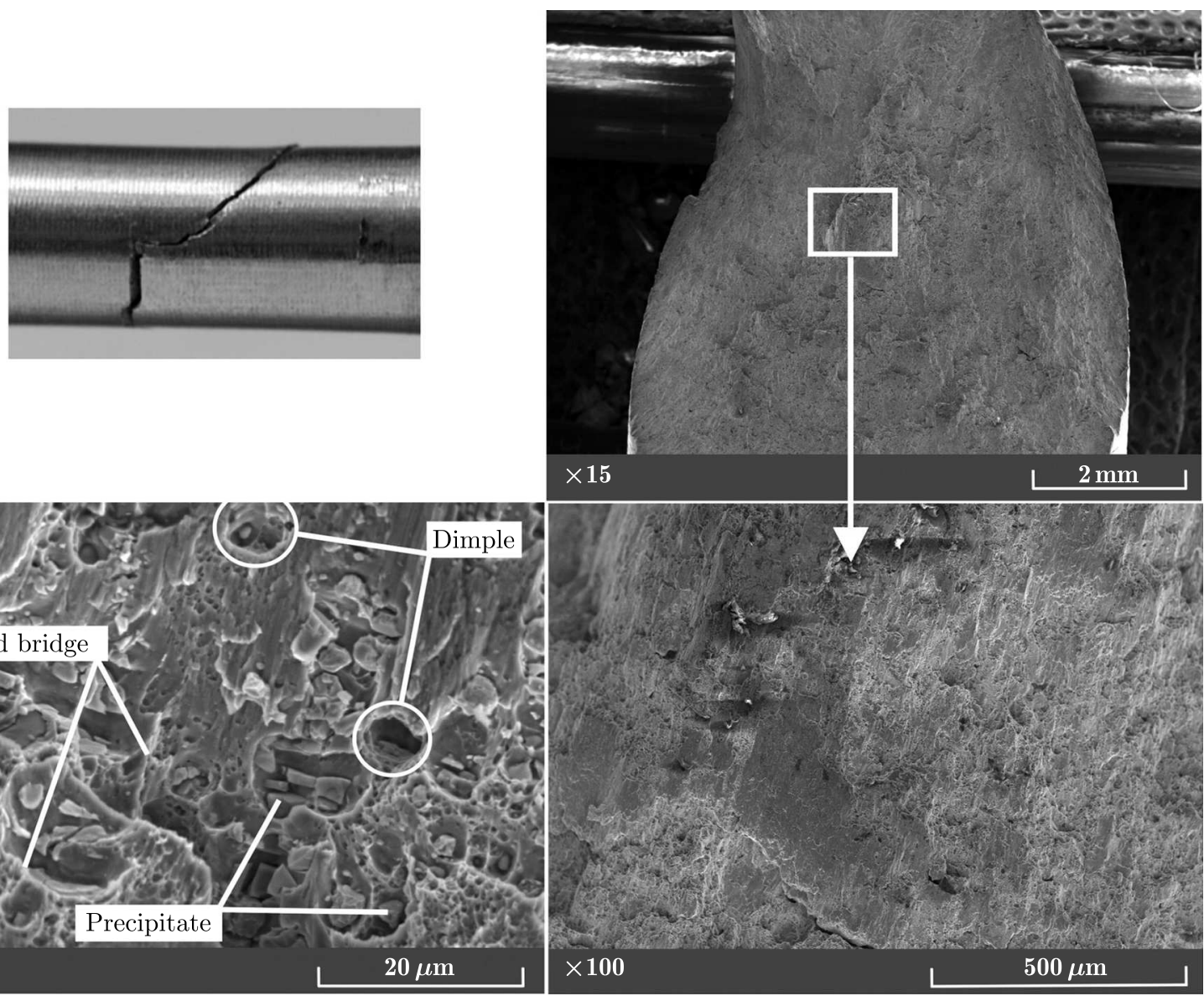

Fig. 2. Specimen fracture obtained in the monotonic tensile test at temperature $20^{\circ} \mathrm{C}$

(a)

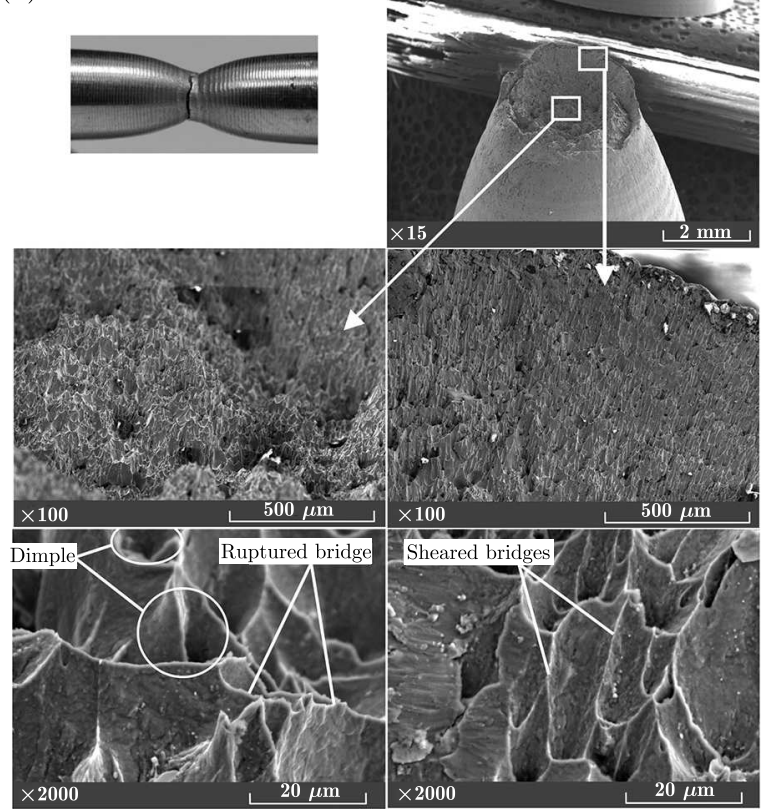

(b)
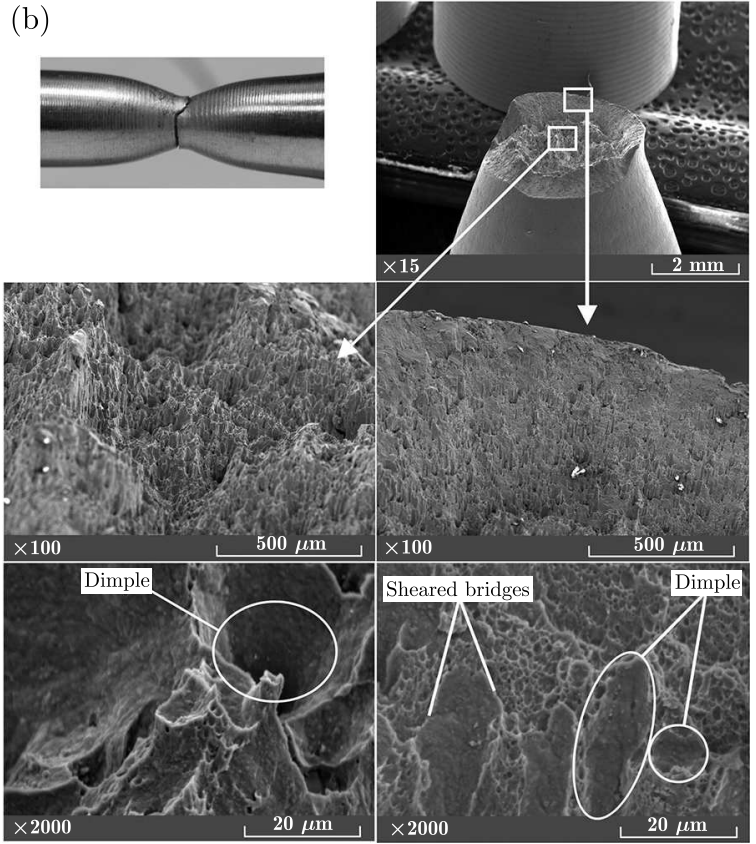

Fig. 3. Specimen fracture surfaces obtained in: (a) monotonic tensile test at a temperature of $300^{\circ} \mathrm{C}$, (b) creep-rupture test at $T=300^{\circ} \mathrm{C}$ and with constant load $F=3.06 \mathrm{kN}$ 
It occupies a much smaller area of the fracture surface than in the case of tension at $300^{\circ} \mathrm{C}$. The fracture mechanism here was fundamentally different than in the case of temperatures of $20^{\circ} \mathrm{C}$ and $100^{\circ} \mathrm{C}$. As a result of necking, the stress state changed from uniaxial to tri-axial with the maximum principal stress $\sigma_{1}$ clearly dominant on the specimen axis. That stress caused crack initiation on the plane perpendicular to the axis in the central part of the specimen cross section. Smaller voids were gradually joined and clearly deformed in the direction of $\sigma_{1}$. Void deformations indicate that higher temperature produced greater deformation.

At the time at which the stress reached the critical value, successive bridges between the voids were ruptured. After this process, the material was suddenly sheared along planes of the maximum shear stress, ultimately causing formation of a fracture. The presence of fine precipitates can be observed at the bottom of pores.

The results obtained over the course of monotonic tensile tests made it possible to estimate loadings in creep tests at different elevated temperatures. At the temperature of $100^{\circ} \mathrm{C}$ a constant loading $F=17.55 \mathrm{kN}$ was applied. At $200^{\circ} \mathrm{C}$ and $300^{\circ} \mathrm{C}$, loadings $F=9.26 \mathrm{kN}$ and $F=3.06 \mathrm{kN}$ were applied respectively. The creep tests were conducted according to EN ISO 204 (2009). The tests were conducted for a series of four specimens at each temperature after which the results of these tests in the form of creep-rupture curves were averaged relative to time.

The fracture surface corresponding to creep-rupture tests at $200^{\circ} \mathrm{C}$ and $300^{\circ} \mathrm{C}$ (Fig. 3b) has a bi-planar nature, similarly as in the case of monotonic tension. However, the part of the surface perpendicular to the specimen axis, mainly related to normal plastic strain, occupies a much larger area in comparison to the shear plane. The fracture mechanism was similar to that observed in Fig. 3a, i.e. material rupturing first took place in the central area of the cross section followed by sudden shearing. The progression of the pore deformation process under the action of constant loading was much slower in comparison to monotonic tension at the same temperature. The much more deformed remnants (dimples) in the direction of the axis left behind after ruptured or sheared bridges between the pores, particularly visible in Fig. 3b, are indicative of this. The nature of fracture in Fig. 3b exhibit similarity to the post-creep fractures obtained by Li et al. (2013) for 2124 alloy. However, it must be noted that, in the cited paper, the creep tests were conducted at a temperature of $260^{\circ} \mathrm{C}$ and tensile stress of 120,130 and $140 \mathrm{MPa}$. The fractures presented in this paper were obtained for $275 \mathrm{MPa}$ and $200^{\circ} \mathrm{C}$ as well as $90 \mathrm{MPa}$ and $300^{\circ} \mathrm{C}$ (Fig. 3b). The growth of voids due to the increase of loading during creep at constant temperature was demonstrated here. However, a similar effect can be achieved by e.g. increasing temperature in the creep process.

\subsection{Monotonic tensile test for the material with pre-deformation}

The level of strain for creep pre-deformation was determined on the basis of averaged creep-rupture curves. It was decided to adopt two different strain levels corresponding to the beginning of the secondary creep $\varepsilon_{s}$ and a certain tertiary creep $\varepsilon_{t}$. This means that the process of preliminary creep in one series of specimens, at a given temperature and under a given loading, lasted until the strain $\varepsilon_{s}$ was reached, and in the second series - until strain $\varepsilon_{t}$ was reached. Unloading of the measuring base of specimens, after the set strain levels were reached, took place at a rate of $2 \mathrm{~mm} / \mathrm{min}$. The specimens were cooled at room temperature. $\varepsilon_{s}$ and $\varepsilon_{t}$ strain values could differ depending on temperature at which tests were conducted. In the case of creep at $100^{\circ} \mathrm{C}, \varepsilon_{s}=10 \%$ and $\varepsilon_{t}=15 \%$ strain levels were applied. At $200^{\circ} \mathrm{C}$ and $300^{\circ} \mathrm{C}$, levels $\varepsilon_{s}=0.6 \%, \varepsilon_{t}=2.3 \%$ and $\varepsilon_{s}=0.4 \%, \varepsilon_{t}=2.3 \%$ were applied respectively. Ultimately, two series of specimens pre-deformed in the creep process at a set temperature were obtained, and each series consisted of 3 specimens. They were subjected to monotonic tensile tests at room temperature in order to determine basic strength parameters. The values of basic strength parameters obtained on the basis of the nominal curves and the critical stress and strain values $\sigma_{c}$ 
and $\varepsilon_{c}$ corresponding to the maximum $\sigma_{1}$ and $\varepsilon_{1}$ are given in Table 2. Figure 4 presents nominal (engineering) monotonic stress-strain curves obtained at room temperature for the specimens previously subjected to pre-deformation at different temperatures and for two different strain levels, as well as the true $\sigma_{1}=\sigma_{1}\left(\varepsilon_{1}\right)$ and $\sigma_{e q}=\sigma_{e q}\left(\varepsilon_{e q}\right)$ curves corresponding to them.

Table 2. Strength parameters obtained for each specimen subjected to preliminary creep and average values for both strain levels (based on the nominal tensile curves) as well as the critical stress and strain values $\sigma_{c}, \varepsilon_{c}$ (based on the true curve $\sigma_{1}=\sigma_{1}\left(\varepsilon_{1}\right)$ )

\begin{tabular}{|c|c|c|c|c|c|c|c|c|c|}
\hline$T\left[{ }^{\circ} \mathrm{C}\right]$ & $\varepsilon_{s}[\%]$ & $\varepsilon_{t}[\%]$ & $E[\mathrm{GPa}]$ & $\sigma_{y}[\mathrm{MPa}]$ & $\sigma_{u}[\mathrm{MPa}]$ & $\sigma_{c}[\mathrm{MPa}]$ & $\varepsilon_{u}[\%]$ & $\varepsilon_{B}[\%]$ & $\varepsilon_{c}[\%]$ \\
\hline \hline \multirow{2}{*}{100} & 10 & - & 71.6 & 598 & 610 & 680 & 4.6 & 5.3 & 7.1 \\
\cline { 2 - 10 } & - & 15 & 72.1 & 635 & 640 & 673 & 2.7 & 2.7 & 3.5 \\
\hline \multirow{2}{*}{200} & 0.6 & - & 74.1 & 475 & 550 & 716 & 7.9 & 13.9 & 20.8 \\
\cline { 2 - 10 } & - & 2.3 & 74.1 & 443 & 490 & 642 & 4.9 & 13.1 & 25.3 \\
\hline \multirow{2}{*}{300} & 0.4 & - & 71.2 & 255 & 363 & 518 & 7.1 & 17.9 & 36.5 \\
\cline { 2 - 10 } & - & 2.3 & 72.6 & 186 & 316 & 380 & 8.7 & 13.1 & 15.2 \\
\hline
\end{tabular}

Let us note that creep at $200^{\circ} \mathrm{C}$ and $300^{\circ} \mathrm{C}$ took place under lower loading than that corresponding to the yield point, and at $100^{\circ} \mathrm{C}$ - under a higher loading. Therefore, in the latter case, the hardening process related to crossing of the yield point and unloading of the specimen mostly dictated the material properties after the creep pre-deformation process. Thus, the significant increase of the offset yield stress compared to the original material can be observed, with a simultaneous decrease of total elongation (Fig. 4a). We can observe an interesting situation in the case of pre-deformation $\varepsilon_{s}=0.6 \%$ at a temperature of $200^{\circ} \mathrm{C}$. The creep process, up to the aforementioned, with a relatively low strain value, caused hardening of the material in comparison to the original material, despite the high temperature. The offset yield point increased with simultaneous reduction of the ultimate tensile strength.

(a)

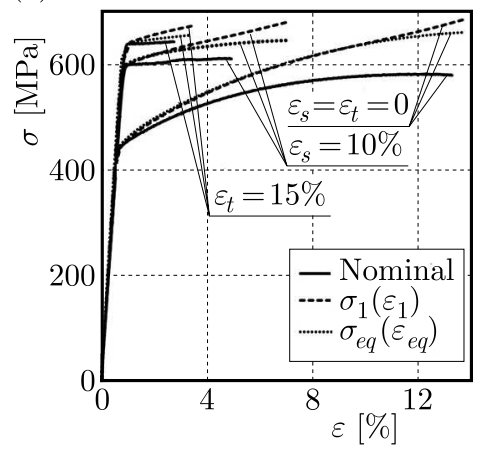

(b)

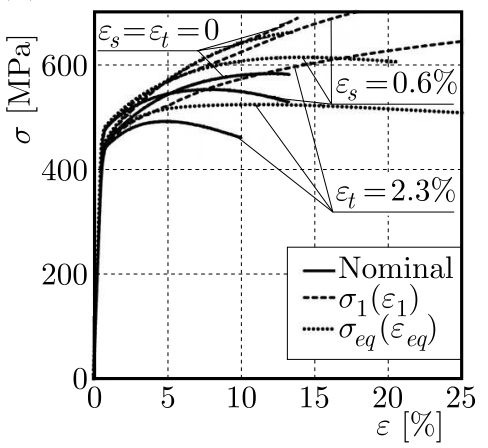

(c)

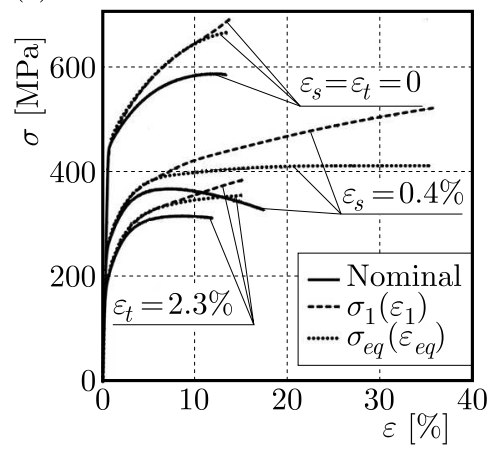

Fig. 4. Nominal (continuous line), actual $\sigma_{1}=\sigma_{1}\left(\varepsilon_{1}\right)$ (dashed line) and $\sigma_{e q}=\sigma_{e q}\left(\varepsilon_{e q}\right)$ (dotted line) monotonic tensile curves obtained for specimens subjected to creep pre-deformation at different temperatures and strain levels against the background of the tensile curve for specimens without pre-deformation at room temperature: (a) $100^{\circ} \mathrm{C}$, (b) $200^{\circ} \mathrm{C}$, (c) $300^{\circ} \mathrm{C}$

The results of numerical simulations in the form of principal and equivalent stress and strain distributions in the specimen transverse plane of symmetry are presented in Fig. 5. They correspond to the situation at the instant at which the specimen ruptured and at which the critical stress and strain values were reached. Due to symmetry, distributions are presented for half of the tested specimen, i.e. for radius $r$ changing from the axis to the exterior surface of the measuring base. In all cases, failure was determined by the principal stress and strain $\sigma_{1}$ and $\varepsilon_{1}$, the value of which always exceeds the equivalent stress and strain in the central area of the cross section, which indicates the presence of a tri-axial stress and strain state. The principal stress 
reaches its maximum values exactly on the specimen axis, while the equivalent stress reaches its minimum on the axis. It should be noted that the equivalent values reach their maximum earlier - before $\sigma_{1}$ and $\varepsilon_{1}$ reach the critical values.

(a)

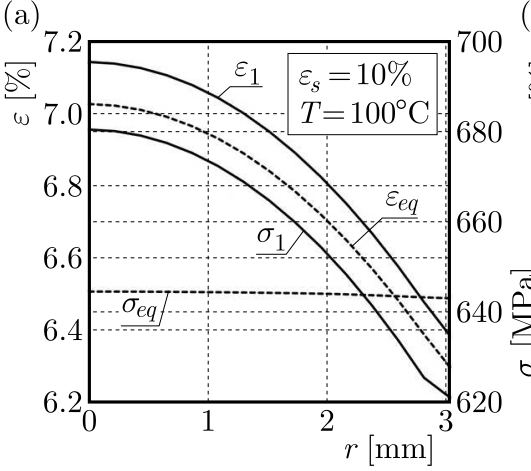

(b)
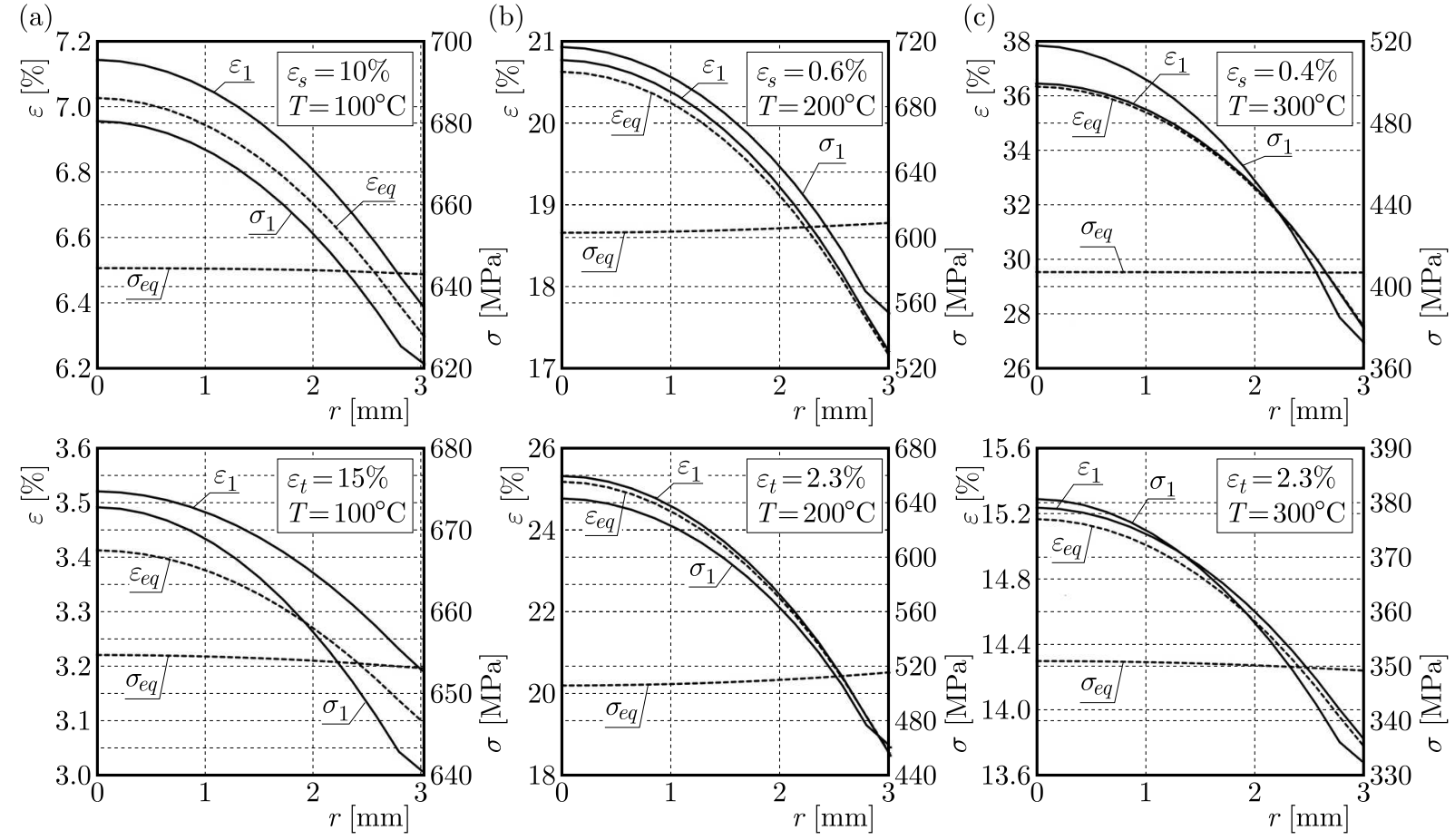

Fig. 5. Distributions of the equivalent stress and strain (dashed line) and the maximum principal stress and strain (continuous line) along the specimen transverse plane of symmetry obtained on the basis of

numerical simulations of tensile tests of the material at room temperature with pre-deformation at temperatures: (a) $100^{\circ} \mathrm{C}$, (b) $200^{\circ} \mathrm{C}$, (c) $300^{\circ} \mathrm{C}$

In the case of the fracture surface obtained in the creep-rupture test at $100^{\circ} \mathrm{C}$, its clear similarity to fracture obtained in the monotonic tensile test at the same temperature can be observed. However, it must be noted that the above mentioned fracture surfaces are characterized by much greater roughness, which is mainly caused by the long-acting load exceeding the material yield point at the set temperature. The maximum shear stress ultimately caused fracture, as indicated by the orientation of the fracture plane. However, the damage was first initiated on the specimen axis as a result of the action of the principal stress. Numerous precipitates found in the remnants left behind after ruptured bridges between the pores in the central part of the cross section are indicative of this. They are not hidden as a result of closure of these remnants by sheared material.

Figures 6 and 7 present examples of fracture surfaces obtained in monotonic tensile tests of specimens (at room temperature) subjected to creep pre-deformation at different temperatures and under different levels of strain. The essential differences between fractures corresponding to tension with creep pre-deformation at $100^{\circ} \mathrm{C}$ (Fig. 6) and fractures of specimens without pre-deformation (Fig. 2) pertain to specimens with pre-deformation $\varepsilon_{t}=15 \%$, which is linked to significant hardening of the material. Here, the fracture surface is made up of two planes, where both are inclined at an identical angle to the specimen vertical axis of symmetry. The temperature at which the pre-deformation took place was too low to enable significant plastic deformation. This is indicated by the remnants left behind by ruptured bridges between the pores in the form of rather small dimples (Fig. 6). The area occupied by these dimples is very small, and in the case of pre-deformation at a level of $\varepsilon_{s}=10 \%$ - almost not visible. 

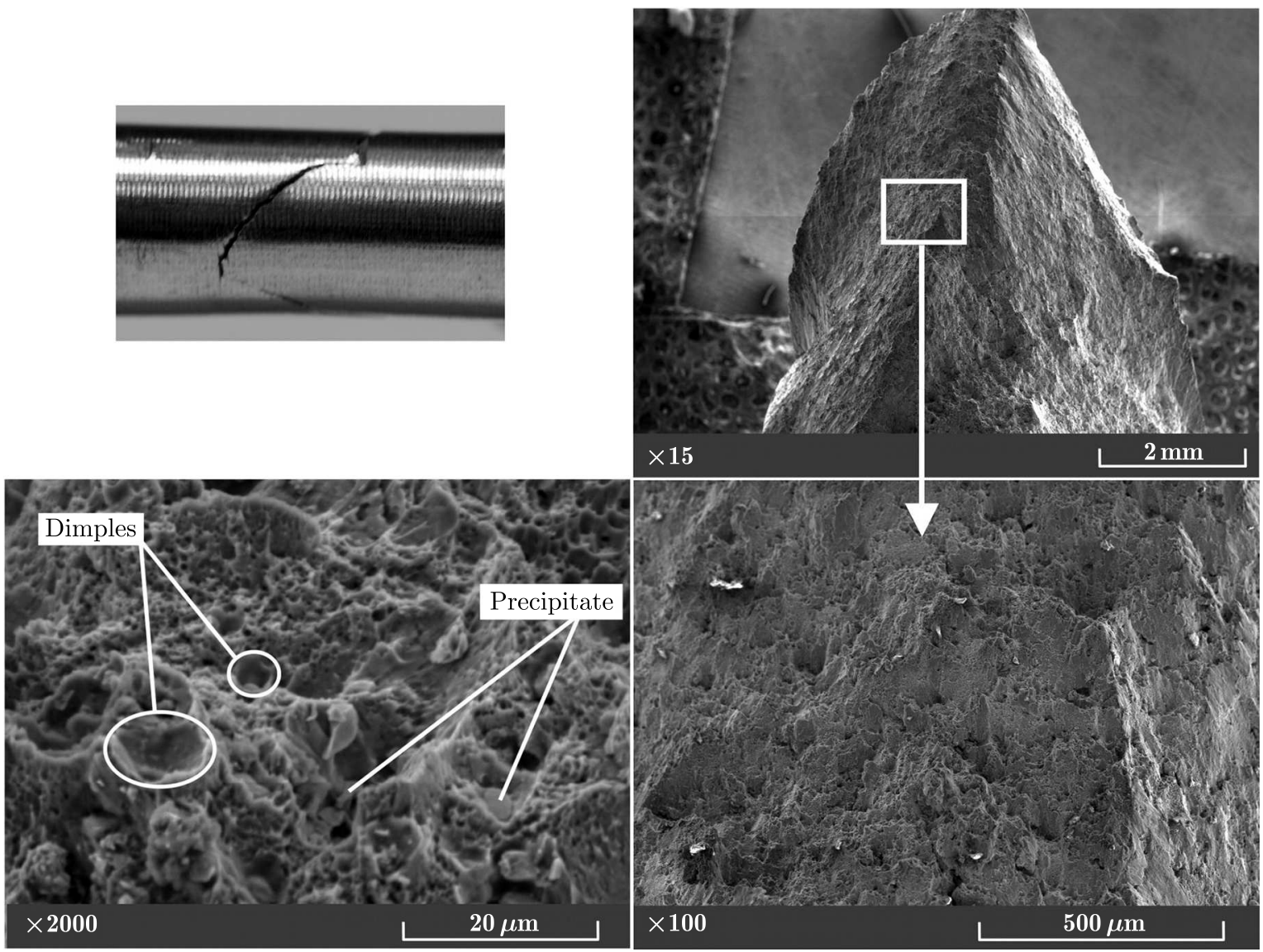

Fig. 6. Example of a fracture surface of the specimen with creep pre-deformation $\left(\mathrm{T}=100^{\circ} \mathrm{C}\right.$, $F=17.55 \mathrm{kN}, \varepsilon_{t}=15 \%$ ) subjected to monotonic tension at room temperature

This may indicate that, in the case of high pre-deformations $\left(\varepsilon_{t}=15 \%\right)$, the fracture process in the monotonic tensile test was initiated in the central part, after which sudden shearing of the material occurred immediately.

There are no significant differences between the fracture surfaces for the material with pre-deformation $\varepsilon_{s}=0.4 \%$ and $\varepsilon_{t}=2.3 \%$ at $300^{\circ} \mathrm{C}$. There exist two planes: the first plane of crack initiation perpendicular to the axis of the specimen and the second plane of shearing (Fig. $7 \mathrm{~b}$ ). The share of the first plane in the fracture surface is much lower here than in the case of tension at $300^{\circ} \mathrm{C}$ (Fig. 3a). For both levels of strain, the voids were joined and clearly deformed in the direction of creep axial loading in the central part of the cross section. After unloading, the voids that were not ruptured took on a spherical shape once again and were ruptured during tension at room temperature, and so, without such strong strains.

The fracture process in the central part of the cross section preceded ultimate shearing of the specimen material. Pre-deformation $\varepsilon_{s}=0.4 \%$ caused a significant decrease in the yield stress and the critical stress, but a strong increase in strain at the moment of the specimen rupture (Fig. 4c). Pre-deformation $\varepsilon_{t}=2.3 \%$ at the same temperature resulted in an even stronger decrease in the yield stress and the critical stress. However, it induced significantly a less increase in strain at the moment of the specimen rupture - the material was thus significantly damaged.

For specimens with pre-deformation at $200^{\circ} \mathrm{C}$, the level of pre-deformation decides about the character of fracture. Let us note that, for pre-deformation $\varepsilon_{s}=0.6 \%$, material hardening occurred first (compared to material without pre-deformation) and softening occurred later (Fig. 4b). No significant material deformation occurred during pre-deformation $\varepsilon_{s}=0.6 \%$ 

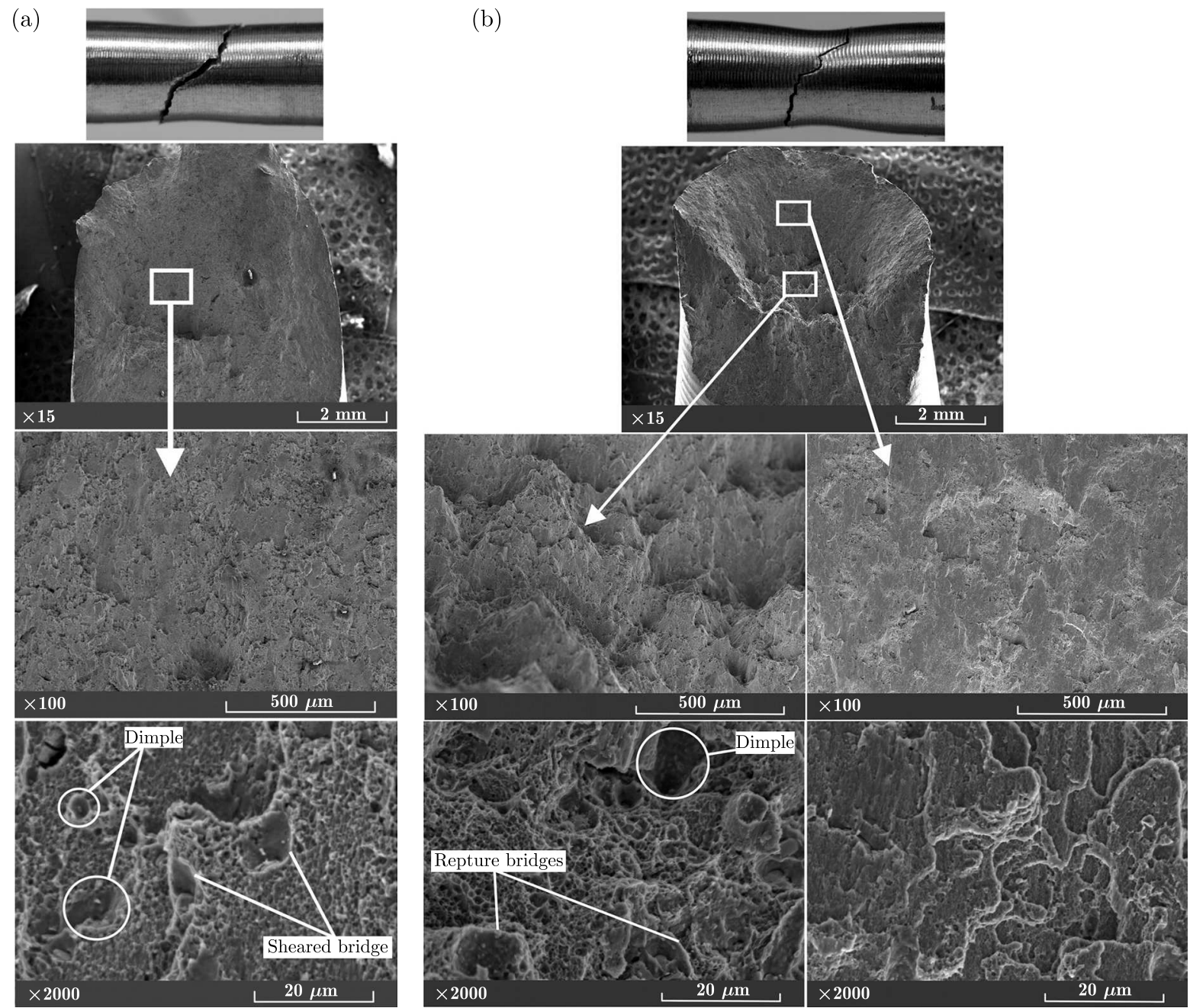

Fig. 7. Example of a fracture surface of the specimen with creep pre-deformation at: (a) $T=200^{\circ} \mathrm{C}$, $F=9.26 \mathrm{kN}, \varepsilon_{s}=0.6 \%$, (b) $T=300^{\circ} \mathrm{C}, F=3.06 \mathrm{kN}, \varepsilon_{t}=2.3 \%$ subjected to monotonic tension at room temperature

there were not many large voids, and their visibly sheared remnants had a spherical character (rather than longitudinal). Sparse precipitates could be observed. The absence of a large number of deep voids after pre-deformation caused the yield point to increase during the monotonic tension process. However, the later growth of these voids caused the material to be incapable of carrying shear stress, resulting in their easy and sudden shearing, which might caused reduction of the ultimate tensile strength. The fracture character was similar here to the fracture obtained in the tensile test of the material with no pre-deformation (Fig. 2).

It is worth emphasizing that the time for which the material is held at elevated temperature is very significant, and this time has also a significant impact on the values of strength parameters (see e.g. Ro et al., 2006; Li et al., 2010; Guo et al., 2013). In the case of pre-deformation at $200^{\circ} \mathrm{C}$, the time was differed significantly for $\varepsilon_{s}=0.6 \%$ (approx. $30 \mathrm{~min}$ ) and $\varepsilon_{t}=2.3 \%$ (approx. $300 \mathrm{~min}$ ). For higher pre-deformation $\left(\varepsilon_{t}=2.3 \%\right)$ the fracture mechanism was very similar to the mechanism in specimens pre-deformed at $300^{\circ} \mathrm{C}$.

It should be pointed out that fractures obtained for specimens with lower pre-deformation $\varepsilon_{s}$ at $100^{\circ} \mathrm{C}$ and $200^{\circ} \mathrm{C}$ are characterized by the presence of a large number of small dimples remnants left behind after small pores. In the case of greater pre-deformation $\varepsilon_{t}$ at the same temperatures, smaller dimples occupy a significantly lesser area. A similar effect was observed in 
the study by Lin et al. (2013b) when temperature was increased at the same stress or when the stress was increased at the same temperature over the course of pre-deformation of alloy 2024 . A similar effect of the pore growth due to rise of stress in creep-rupture tests of alloy 2124 at a temperature of $260^{\circ} \mathrm{C}$ was also obtained by $\mathrm{Li}$ et al. (2013). The character of fracture in the case of specimens with pre-deformation at a temperature of $300^{\circ} \mathrm{C}$ does not exhibit significant differences in terms of the value of this pre-deformation. The plane of crack initiation perpendicular to the specimen axis and shear plane is clearly visible here. The share of the shear plane in the entire area of the fracture is significantly less than, e.g. in the case of tension at $300^{\circ} \mathrm{C}$ (Fig. 3a).

\section{Summary}

This paper presents results of monotonic tensile tests conducted at room temperature and elevated temperature as well as of creep tests conducted at elevated temperature on aluminum alloy EN-AW 2024. It also contains a comparison between monotonic tensile curves obtained for specimens without pre-deformation and with pre-deformation. Specimen fracture surfaces obtained in monotonic tensile and creep tests were also compared, and fundamental differences between them were indicated.

A clear decrease in basic strength parameters, such as Young's modulus, yield point and ultimate tensile strength, was observed with a temperature increase. While this reduction is slight at $100^{\circ} \mathrm{C}$, the parameters drop significantly at $300^{\circ} \mathrm{C}$. The offset yield point and ultimate tensile strength are reduced two-fold compared to the values corresponding to the room temperature. Specimen fracture surfaces obtained in tensile tests at elevated temperature clearly demonstrate that the material plastic properties increase with temperature growth.

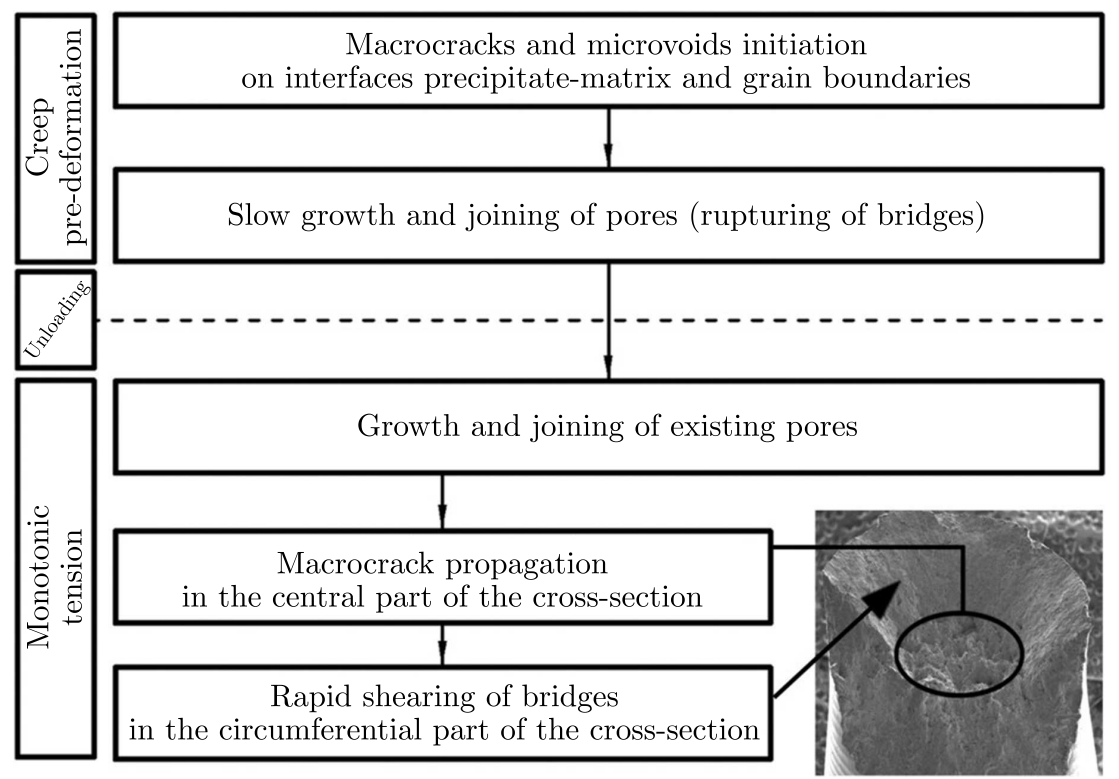

Fig. 8. Schematic representation of damage evolution and failure of the material

Fractographic analysis of the fracture surfaces proves that the following stages can be distinguished in the failure process (Fig. 8):

1. Damage initiation exactly on the specimen axis as a result of the action of maximum principal plastic stress or strain (or both simultaneously) during monotonic tensile or creep tests. This initiation occurs on the boundary between the matrix and precipitate, particularly when the latter has a coarse character. The precipitates visible in fracture surfaces prove this. 
2. Growth and deformation of pores (damage).

3. Joining of pores together by rupturing bridges between them in the central part of the cross section (close to the axis of symmetry). The size of this area depends mostly on temperature and loading, but also on the duration of its action (during creep process).

4. Rapid shearing of the material close to the lateral surface of the specimen along the planes of maximum shear stress. On these planes, the precipitates may be hidden due to closure of the remnants (dimples) left behind after sheared bridges between the pores.

Analysis of the results allows one to observe two antagonistic processes. On the one hand, there occurs material hardening as a result of large plastic deformation and the migration and blocking of dislocations on grain boundaries associated with it. On the other hand, the material is weakened due to nucleation and growth of micro-voids as well as rupturing and shearing of bridges between them. Both mechanisms can be found in problems related to low speed wind turbine generators (see Introduction).

Strong pre-deformations at low temperatures result in a significant increase in the yield strength $\sigma_{y}$ with a slight change in the critical stress $\sigma_{c}$. At the same time, the ductility of the material decreases, which is evidenced by a significant drop in the value of deformations at the moment of sample rupturing. Minor changes in $\sigma_{y}$ and $\sigma_{c}$ are observed at both values of strain $\left(\varepsilon_{s}\right.$ and $\left.\varepsilon_{t}\right)$ for the material with pre-deformation at higher temperature. There is also a strong increase in strain at the moment of specimen rupture. Low creep pre-deformation $\varepsilon_{s}$ at high temperature $300^{\circ} \mathrm{C}$ causes a significant decrease in $\sigma_{y}$ and $\sigma_{c}$ with a simultaneous increase in strain at the moment of sample rupturing. On the other hand, significant pre-deformation $\varepsilon_{t}$ at the same temperature causes an even greater decrease in $\sigma_{y}$ and $\sigma_{c}$. The increase in deformation at the moment of rupture is significantly smaller, which indicates strong earlier damage of the material. Young's modulus does not change significantly due to pre-deformation at elevated temperature.

Creep pre-deformation performed at different temperatures makes it possible to shape the material strength properties. Selection of the proper parameters of this pre-deformation, such as temperature, stress and strain, provides the possibility of improving material characteristics.

\section{Acknowledgement}

The present paper was financially supported by the Ministry of Science and Higher Education of Poland (research project No. S/WM/4/2017) and realized at Bialystok University of Technology.

\section{References}

1. Chakherlou T.N., Aghdam A.B., Akbari A., Saeedi K., 2010, Analysis of cold expanded fastener holes subjected to short time creep: Finite element modelling and fatigue tests, Materials and Design, 31, 2858-2866

2. Chen J.F., Zhen L., Jiang J.T., Yang L., Shao W.Z., Zhang B.Y., 2012, Microstructures and mechanical properties of age-formed 7050 aluminum alloy, Materials Science and Engineering: A, 539, 115-123

3. Derpenski L., SeWeryn A., 2011, Experimental research into fracture of EN-AW 2024 and EN-AW 2007 aluminum alloy specimens with notches subjected to tension, Experimental Mechanics, 51, 1075-1094

4. EN ISO 204, 2009, Metallic materials, uniaxial creep testing in tension: Method of test

5. EN ISO 6892-1, 2016, Metallic materials, tensile testing-Part 1: Method of test at room temperature

6. EN ISO 6892-2, 2011, Metallic materials, tensile testing -Part 2: Method of test at elevated temperature 
7. Guo W., Yang M., Zheng Y., Zhang X., Li H., Wen X., Zhang J., 2013, Influence of elastic tensile stress on aging process in an Al-Zn-Mg-Cu alloy, Materials Letters, 106, 14-17

8. Haigen W., Fuzhong X., Mingpu W., 2017, Effect of ingot grain refinement on the tensile properties of $2024 \mathrm{Al}$ alloy sheets, Materials Science and Engineering: A, 682, 1-11

9. Ho K.C., Lin J., DeAn T.A., 2004, Constitutive modelling of primary creep for age forming an aluminium alloy, Journal of Materials Processing Technology, 153-154, 122-127

10. Karakaş Ö., Szusta J., 2016, Monotonic and low cycle fatigue behaviour of 2024-T3 aluminium alloy between room temperature and $300^{\circ} \mathrm{C}$ for designing VAWT components, Fatigue and Fracture of Engineering Materials and Structure, 39, 95-109

11. Kowalewski Z.L., Szymczak T., Maciejewski J., 2014, Material effects during monotonic-cyclic loading, International Journal of Solids and Structures, 51, 740-753

12. Kumar P., LeBlanc J., Shukla A., 2011, Effect of curvature on shock loading response of aluminum panels, [In:] Dynamic Behavior of Materials, Proulx T. (Ed.), Vol. 1, Springer, 369-374

13. Li C., Wan M., Wu X.-D., HuAng L., 2010, Constitutive equations in creep of 7 B04 aluminum alloys, Materials Science and Engineering: A, 527, 3623-3629

14. Li L.-T., Lin Y.C., Zhou H.-M., Jiang Y.-Q., 2013, Modeling the high temperature creep behaviors of 7075 and 2124 aluminum alloys by continuum damage mechanics model, Computational Materials Science, $\mathbf{7 3}, 72-78$

15. Lin Y.C., Jiang Y.-Q., Xia Y.-C., Zhang X.-C., Zhou H.-M., Deng J., 2014, Effects of creep-aging processing on the corrosion resistance and mechanical properties of an $\mathrm{Al}-\mathrm{Cu}-\mathrm{Mg}$ alloy, Materials Science and Engineering: A, 605, 192-202

16. Lin Y.C., Xia Y.-C., Chen M.-S., Jiang Y.-Q., Li L.T., 2013a, Modeling the creep behavior of 2024-T3 Al alloy, Computational Materials Science, 67, 243-248

17. Lin Y.C., Xia Y.-C., Jiang Y.-Q., Zhou H.-M., Li L.-T., 2013b, Precipitation hardening of 2024-T3 aluminum alloy during creep aging, Materials Science and Engineering: A, 565, 420-429

18. Lumley R.N., Morton A.J., Polmear I.J., 2002, Enhanced creep performance in an Al-Cu-Mg-Ag alloy through underageing, Acta Materialia, 50, 3597-3608

19. NAimi A., Yousfi H., Trari M., 2013, Influence of cold rolling degree and ageing treatments on the precipitation hardening of 2024 and 7075 alloys, Mechanics of Time-Dependent Materials, 17, $285-296$

20. Ro Y.J., Begley M.R., Gangloff R.P., Agnew S.R., 2006, Effect of aging on scale-dependent plasticity in aluminum alloy 2024, Materials Science and Engineering: A, 435-436, 333-342

21. Singh A.K., Ghosh S., Mula S., 2016, Simultaneous improvement of strength, ductility and corrosion resistance of Al2024 alloy processed by cryoforging followed by ageing, Materials Science and Engineering: A, 651, 774-785

22. Szusta J., Seweryn A., 2017, Experimental study of the low-cycle fatigue life under multiaxial loading of aluminum alloy EN AW-2024-T3 at elevated temperatures, International Journal of Fatigue, 96, 28-42

23. Tomczyk A., Koniuszewski R., 2017, Construction of a System for Measuring Sample Elongations at Elevated Temperatures Using Devices Intended for Work at Room Temperature (in Polish), Patent No. PL 68955 Y1

24. WANG H., Yi Y., HuAng S., 2016, Influence of pre-deformation and subsequent ageing on the hardening behavior and microstructure of 2219 aluminum alloy forgings, Journal of Alloys and Compounds, 685, 941-948

25. WAng Y.G., JiAng Z.G., WAng L.L., 2013, Dynamic tensile fracture behaviours of selected aluminum alloys under various loading conditions, Strain, 49, 335-347 
26. Yang Y., Zhan L., Ma Q., Feng J., Li X., 2016, Effect of pre-deformation on creep age forming of AA2219 plate: Springback, microstructures and mechanical properties, Journal of Materials Processing Technology, 229, 697-702

27. Yang Y., Zhan L., Shena R., Yin X., Li X., Li W., Huang M., He D., 2017, Effect of pre-deformation on creep age forming of 2219 aluminum alloy: Experimental and constitutive modelling, Materials Science and Engineering: A, 683, 227-235

28. Zhan L., Lin J., DeAn T.A., HuAng M., 2011, Experimental studies and constitutive modelling of the hardening of aluminium alloy 7055 under creep age forming conditions, International Journal of Mechanical Sciences, 53, 595-605

29. Zhang J., Deng Y., Zhang X., 2013, Constitutive modeling for creep age forming of heat-treatable strengthening aluminum alloys containing plate or rod shaped precipitates, Materials Science and Engineering: A, 563, 8-15

30. Zhao Y.L., Yang Z.Q., Zhang Z., Su G.Y., Ma X.L., 2013, Double-peak age strengthening of cold-worked 2024 aluminum alloy, Acta Materialia, 61, 1624-1638

Manuscript received January 29, 2018; accepted for print March 6, 2018 